\title{
Variety and Sulfite Levels Affect Microbial and Sensory Properties of Dehydrated Jackfruit (Artocarpus heterophyllus Lam.) During Storage
}

\author{
Lorina A. Galvez \\ Department of Food Science \& Technology \\ Visayas State University, Visca, Baybay, City, Philippines
}

\begin{abstract}
One of the problems of the dehydrated jackfruit produced in Visayas State University (VSU) is the development of browning after 1 to 2 months of storage. This study was conducted to determine the effects of variety and sulfite on the sensory and microbial quality of the product during 4 months storage at ambient temperature. Two jackfruit varieties (AES-1 and AES-2) and two levels of sulfite $(0.1 \% \& 0.2 \% \mathrm{w} / \mathrm{w})$ were used in the study. Treatments were laid out in CRD with three replications. Data were subjected to Analysis of variance (ANOVA) at 5\% level of significance employing SPSS version 16 . The treatments means were compared using Tukey's HSD (Honestly Significant Difference at $5 \%$ level) and Wilcoxon Signed Ranks Test( $5 \%$ level). All of the analyses were carried out in triplicate sample.

Longer storage caused the deterioration of the product color due to browning reaction. Slow occurrence of the sensorial changes occurred which can be attributed to the variety and sulfite levels. Sulfiting stabilized the microbial count (aerobic microorganisms or the molds). As the storage time was lengthened, the microbial count generally increased after the fourth month of storage; however, the microbial counts were still within the acceptable limits. The absence of E. coli and Salmonella proved the product to be safe for human consumption until four months of storage.
\end{abstract}

Keywords: Sensory properties, dehydrated jackfruit, microbial properties, AES-1 and AES2 varieties

\section{INTRODUCTION}

The current awareness of consumers on the importance of good health created an increasing demand for safe and quality food products. Shelf life of the product is a determinant of its safety and quality. During processing and storage, browning of the food product occurs especially when subjected to mechanical injury. It is responsible for the deterioration of the food product since the flavor, appearance, and nutritive value of the food product are affected (Eskin 1990). Browning becomes one of the visible problems in marketing resulting to profit losses among food processors (Lambrecht 1995).

The sensory and microbial properties of the product can be assessed to ensure its safety and quality. Browning can be addressed by the addition of sulfites which possess antimicrobial activity and inhibit both enzymatic and non-enzymatic reactions. Madero and Finne (1982), as cited by Marshall et al. (2000) proposed that bisulphate exerted a competitive inhibitory effect on polyphenol oxidase by binding a sulphydryl group at the 
active site of the enzymes. Ascorbic acid and sulfites reduce quinones back to the original colorless phenols, or react irreversibly with quinones to form stable colorless products (Ashie et al. 1996).

One of the tropical fruits with a high processing potential is jackfruit. It is a delicious composite fruit with succulent and firmly textured bulbs. It is grown extensively in several countries including the Indian sub-continent, southern China, Southeast Asian, middle Africa, and Latin America (Samaddar 1985 as cited in Saxena et al. 2009).

Jackfruit, the largest edible fruit, is widely grown in the Philippines weighing as much as $50 \mathrm{~kg}$ (Coronel 1983). Every $100 \mathrm{~g}$ edible portion (pulp) contains 84\% $\mathrm{H}_{2} \mathrm{O}, 18 \mathrm{~g}$ carbohydrates, $1.9 \mathrm{~g}$ proteins, $0.1 \mathrm{~g}$ fat, $1.1 \mathrm{~g}$ fiber, $30 \mathrm{mg} \mathrm{Ca}, 287 \mathrm{mg} \mathrm{K}, 0.5 \mathrm{mg} \mathrm{Fe}$, vitamin A 50 U.I. and thiamine 30 U.I. (Abraham et. al. 2004).

In Western, Central, and Eastern Visayas jackfruit is one of the priority commodities for research (Cruz, 2002). Efforts have been done for the identification and propagation of promising accessions to increase jackfruit production in the region for processing. The fruit, however, is climacteric and deteriorates rapidly upon ripening. Saxena et al. (2008) described a process for extending the shelf-life of jackfruit bulbs through minimal processing coupled with modified atmosphere storage. A multi-target preservation technique or hurdle technology could be adopted so that the bulbs can have a firm texture with no tissue disintegration and acidic $\mathrm{pH}$. The hurdles of multi-target strategy could be water activity $\left(A_{w}\right)$ regulation, acidification, mild heat treatment, with no emphasis on broad-spectrum antimicrobial agents and active packaging (Vibhakara 2007, as cited in Saxena et al. 2009).

The Visayas State University in Leyte developed a processing technology on food dehydration, where there is virtually complete water removal under controlled conditions. This causes minimum or ideally no other changes in the food properties. There is less water for microbe development which is an important factor in food preservation (Lenart 1996 as cited in El-Aouar et al. 2003). The processing technology involves a sulfite-free dehydrated jackfruit (Diamante, 2005) which is safer for consumers who are asthmatics since sulfite is known to trigger asthma (Marshall et al. 2000).

During the course of commercialization, however, it was observed that browning developed after one to two months of storage, reducing the salability and shelf life of the product. There are limited data on the sensory and microbiological properties of dehydrated jackfruit in the Philippines. This study aimed to determine the effects of sulfite levels and variety on the sensory and microbiological properties of dehydrated jackfruit.

\section{MATERIALS AND METHODS}

\section{Raw Materials}

Two jackfruit varieties with right maturity were procured from Inopacan, Leyte (AES2) and Ormoc City Philippines (AES-1). The fruits were brought to the Department of Food Science and Technology, VSU, Visca, Baybay City, Leyte in April 2010 for processing. Sodium metabisulfite, citric acid, and sodium benzoate were obtained from the jackfruit processing plant; sugar was bought from the market in Baybay City.

\section{ExperimentalDesign}

The study used 2 factorial designs arranged in completely randomized design (CRD), with variety (V1-AES-1 \& V2-AES-2) as factor 1 and sulfite levels $(0.1 \% \& 0.2 \% \mathrm{w} / \mathrm{w})$ as factor 2. There were a total of 4 treatments $(\mathrm{T} 1=\mathrm{V} 1-0.1, \mathrm{~T} 2=\mathrm{V} 1-0.2, \mathrm{~T} 3=\mathrm{V} 2-0.1$ and $\mathrm{T} 4=\mathrm{V} 2-0.2)$. The study was replicated three times. 


\section{Dehydration Process}

The fruits were washed, rinsed with chlorinated water (100 ppm), and sliced along the lateral axis into halves. The pulps were taken, deseeded, halved and boiled in $75 \%(\mathrm{w} / \mathrm{w})$ sugar syrup for $35 \mathrm{~min} / 15 \mathrm{~kg}$ (AES-1) and $60 \mathrm{~min} / 15 \mathrm{~kg}$ (AES-2) for time of doneness. Samples were cooled and added with different amounts of preservatives in each variety as follows: $\mathrm{P}_{1}=0.1 \%$ sulfite $+0.1 \%$ sodium benzoate $+0.3 \% \mathrm{w} / \mathrm{w}$ citric acid, $\mathrm{P}_{2}=0.1 \% \mathrm{w} / \mathrm{w}$ sulfite $+0.1 \% \mathrm{w} / \mathrm{w}$ sodium benzoate $+0.3 \% \mathrm{w} / \mathrm{w}$ citric acid. The samples were soaked in syrup concentration for $24 \mathrm{~h}$, drained, and rinsed with previously boiled cold water. The samples were laid on the trays and dried at ambient humidity $\left(70^{\circ} \mathrm{C}\right.$ for $\left.8 \mathrm{~h}\right)$ with loading density of $60 \mathrm{~kg} / 8$ trays. The dried samples with $10-12 \% \mathrm{MC}$ were allowed to sweat overnight, packed in a laminated tin foil bag and stored for 4 months in opaque plastic containers at ambient temperature ready for different analyses.

\section{Sensory Evaluation}

The dehydrated pulps from two varieties with different levels of sulfite were subjected to sensory evaluation following standard protocol of Mabesa (1986). A total of twenty-five evaluators (junior Food Technology students and staff members) of VSU evaluated the product. The sensory parameters included color, aroma (jackfruity), flavor (jackfruity), aftertaste, and texture using the intensity quality scoring with 7-point scale with 1 as the lowest intensity score and 7 as the highest intensity score. General acceptability was evaluated using the 7-point Hedonic scale with 1 as dislike very much and 7 as like very much. Sensory evaluation was done every month for 4 months to monitor the changes with time using the same group of panelists.

\section{Microbiological Assay}

The different samples were microbiologically analyzed every two months using PCA and PDA following standard protocol. The microbiological analysis was performed simultaneously with the sensory evaluation of the dehydrated products. Plate count agar (PCA) was used to determine the total aerobic plate count. Potato dextrose agar (PDA) acidified to $\mathrm{pH} 3.5$ with $10 \%$ tartaric acid was used to determine the mold count. Microbial counts were reported as colony forming units $(\mathrm{cfu}) / \mathrm{g}$ or $\log \mathrm{cfu} / \mathrm{g}$ sample. The 4 treatments were also submitted for E. coli and Salmonella spp. analyses at the Department of Veterinary Medicine, VSU.

\section{Statistical Analyses}

The effects of sulfite level and variety on the sensory and microbiological data obtained were analyzed by subjecting data to analysis of variance (ANOVA) at 5\% level of significance employing SPSS 16. The treatments means were compared using HSD (Honestly Significant Difference at 5\% level). Comparison of the sensory properties of two varieties was done using Wilcoxon Signed Ranks Test (2-related samples) during the 4month storage. All of the analyses were carried out in triplicate sample.

\section{RESULTS AND DISCUSSION}

\section{Sensory Evaluation}

Color. Generally an increasing trend of the color intensity for both T1 (AES-1 \&0.1\% sulfite) and T2 (AES-1 \& $0.2 \%$ sulfite)were observed which means the product was 
becoming brown with storage; however no significant difference with time was observed. Comparing the two treatments (Table 1), a significant difference was observed only after the first month. The results imply that at any sulfite level no color change was evident except after the first month. T3 (AES- 2 \& $0.1 \% \mathrm{w} / \mathrm{w}$ sulfite) showed no difference in color intensity taken at the start and 1 month, and after two to four months there was still no difference observed. The color of T3 was more or less the same at the later stage but generally values were increasing which suggests that there is browning of the product with time During the first two months, there was no difference in color observed in T4 (AES-2 $\& 0.2 \% \mathrm{w} / \mathrm{w}$ sulfite). The same observation was noted during the third and fourth months; however, a difference existed when it was compared with the earlier months. A big difference of the color was observed if the time gap was wide (Table 1). The intensity of the color was going up which means browning occurred (Fig. 1). This color loss could be attributed to non-enzymatic browning (Rahman and Perera, 2007). There was no significant difference between T3 and T4 (Table 2) which implies that sulfite level did not affect the color with storage in AES-2 jackfruit variety.

Table 1. Intensity values for different sensory parameters of dehydrated jackfruit during 4 months storage at room temperature.

\begin{tabular}{lcccccc}
\hline Parameter & Treatment & \multicolumn{5}{c}{ Storage, Month } \\
\cline { 2 - 6 } Color & & 0 & 1 & 2 & 3 & 4 \\
& T1 & $3.48 a$ & $3.40 a$ & $3.60 a$ & $3.64 a$ & $4.16 a$ \\
& T2 & $2.84 a$ & $2.68 a$ & $3.12 a$ & $3.60 a$ & $3.60 a$ \\
& T3 & $2.52 c$ & $3.12 b c$ & $3.92 a b$ & $3.88 a b$ & $4.44 a$ \\
& T4 & $3.04 c$ & $3.72 b c$ & $3.88 a b c$ & $4.20 a b$ & $4.64 a$ \\
\hline Aroma & T1 & $4.56 a$ & $4.64 a$ & $4.48 a$ & $4.60 a$ & $4.44 a$ \\
& T2 & $4.40 a$ & $5.32 a$ & $5.08 a$ & $5.40 a$ & $5.08 a$ \\
& T3 & $4.56 a$ & $4.04 a$ & $4.56 a$ & $4.80 a$ & $4.48 a$ \\
& T4 & $3.84 a$ & $5.04 a$ & $5.08 a$ & $5.23 a$ & $4.88 a$ \\
\hline Flavor & T1 & $4.64 a$ & $4.80 a$ & $4.80 a$ & $4.52 a$ & $4.52 a$ \\
& T2 & $4.48 b$ & $5.00 a b$ & $5.08 a b$ & $5.52 a$ & $5.24 a b$ \\
& T3 & $4.80 a$ & $4.72 a$ & $4.56 a$ & $4.60 a$ & $4.56 a$ \\
& T4 & $3.56 a$ & $4.32 a$ & $4.56 a$ & $4.60 a$ & $4.04 a$ \\
\hline Aftertaste & T1 & $4.24 a$ & $3.76 a$ & $4.0 a$ & $3.84 a$ & $4.40 a$ \\
& T2 & $4.00 a$ & $3.72 a$ & $4.08 a$ & $4.56 a$ & $4.48 a$ \\
& T3 & $4.40 a$ & $4.64 a$ & $4.52 a$ & $3.84 a$ & $4.56 a$ \\
& T4 & $3.84 a$ & $4.68 a$ & $4.28 a$ & $4.04 a$ & $4.48 a$ \\
\hline Texture & T1 & $4.68 a$ & $4.00 a$ & $4.96 a$ & $4.92 a$ & $4.60 a$ \\
& T2 & $4.68 a$ & $4.36 a$ & $4.40 a$ & $4.68 a$ & $4.64 a$ \\
& T3 & $5.00 a$ & $4.48 a$ & $4.92 a$ & $4.48 a$ & $4.56 a$ \\
& T4 & $5.12 a$ & $4.12 a$ & $4.80 a$ & $4.88 a$ & $4.88 a$ \\
\hline
\end{tabular}

${ }^{1} \mathrm{~N}=3$. Means in the same row with same letters are not significantly $(P \leq 0.05)$ different with each other. T1 (AES$1 \& 0.1 \% \mathrm{w} / \mathrm{w} /$ Sulfite), T2 (AES- $1 \& 0.2 \% \mathrm{w} / \mathrm{w} /$ Sulfite), T3(AES- $2 \& 0.1 \% \mathrm{w} / \mathrm{w} /$ Sulfite) and T4(AES- $2 \& 0.2 \%$ $\mathrm{w} / \mathrm{w} /$ Sulfite) ;Color (1-yellow to 7-brown),Aroma(1-weak jackfruitty aroma to 7-strong),flavor(1-weak jackfruitty flavor to 7-strong), aftertaste (1-none to 7-perceptible) and texture (1-soft to 7-chewy).

Aroma. The intensity scores of the 4 treatments were not affected by time of storage (Table 1) as perceived by the panelists. The result implies that at any variety and sulfite levels the aroma was not affected until four months of storage. T1 (AES-1 \&0.1\%w/w sulfite) and T2 (AES-1 \& $0.2 \% \mathrm{w} / \mathrm{w}$ sulfite) were not different with respect to aroma until two months but after 3 and 4 months, they were different from each other.(Table 2). T2 was more aromatic (jackfruitty) than T1 which could be speculated that higher sulfite enhanced the jackfruitty aroma in the product in this variety. But generally, the aroma intensity declined for treatments with lower sulfite for both varieties; however, aroma intensity 


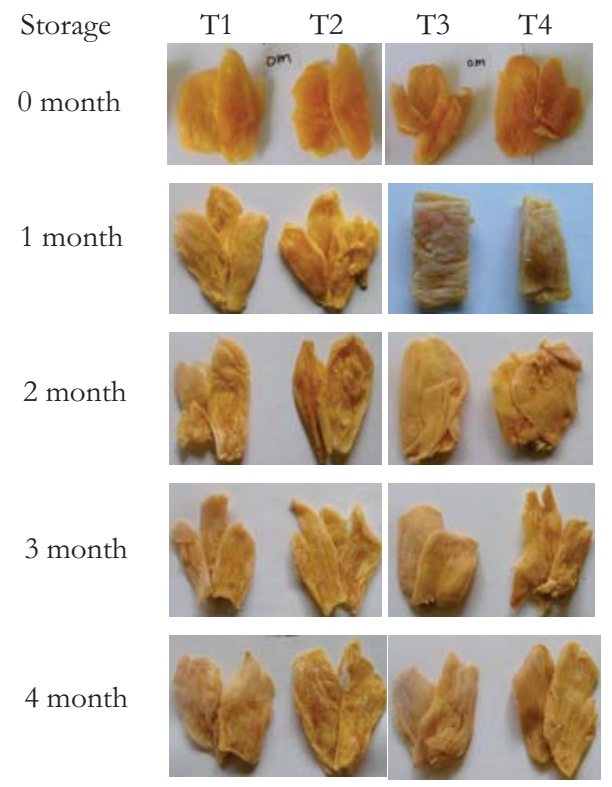

Figure 1. Color observations of dehydrated jackfruit stored for 4 months. T1 (AES- 1 \& $0.1 \% \mathrm{w} /$ wsulfite) T2 (AES-1 \& $0.2 \% \mathrm{w} / \mathrm{w}$ sulfite), T3 (AES- $2 \& 0.1 \% \mathrm{w} /$ wsulfite) and T4 (AES- $2 \& 0.2 \% \mathrm{w} / \mathrm{w}$ sulfite).

increased with higher sulfite in both varieties. This showed that as the storage continued, the aromatic components volatilized; however, if more sulfite was present, aroma intensity was intensified. However, for AES- 2 treatments (T3 \& T4) during the course of storage, no significant difference was observed by the panelists (Table 2). But worth noting was the declining trend of the aroma intensity as perceived by the panel (Table 1).

Flavor. It was observed that T1, T3, and T4 showed no significance for the flavor intensity with storage except T2 (Table 1). Generally, the flavor intensity increased with storage and was lowest at the start of storage. T1 and T2 were not different with each other after 3 and 4 months of storage (Table 2). However, significant difference existed after 0,1 , and 2 months. Meanwhile, T3 and T4 were not different from each other with time except at the start of storage (Table 2). Furthermore, at the start of storage T3 had more jackfruitty flavor than T4. Probably at the start of storage, T4 had a dominant flavor coming from sulfite and less of jackfruitty flavor. But as the storage continued, the panel did not detect any difference with respect to the flavor of the two treatments. Generally, it was noted that AES-1 treatments (T1 \& T2) were more aromatic and flavorful (jackfruitty) than AES-2 treatments (T3 \& T4). The variations observed may be linked to the nature of the raw material, its chemical composition, and/or its structure that influenced the intensity of the mass transfer phenomena and other reactions leading to the formation of compounds involved in texture and flavor perception (Torregani and Bertolo, 2001 as cited in Konopacka et al. 2009).

Aftertaste. No difference was observed for all of the treatments (T1, T2, T3 \& T4) from the start to the end of storage period (Table 1). Aftertaste of the dehydrated product was not affected by sulfite concentration or jackfruit variety. T1 was not significantly different with T2 throughout the storage duration except after 3 months, where T2 was significantly more perceptible in aftertaste (Table 2 ). This indicated that T2 had dominant aftertaste which could be contributed by the higher sulfite level. On the other hand, both T3 and T4 had comparable aftertaste throughout the duration of storage (Table 2) which implies that sulfite level did not cause significant variation in the aftertaste of AES-2 variety. 
Texture. The texture intensity revealed that all of the treatments (T1, T2. T3 \& T4) showed a non- significant difference from the start until four months of storage (Table 1).

Also the comparison of the texture intensity showed that between AES-1 \& $0.1 \%$ and AES- $1 \& 0.2 \% \mathrm{w} / \mathrm{w}$ or between AES- $2 \& 0.1 \%$ and AES- $2 \& 0.2 \% \mathrm{w} / \mathrm{w}$, a non-significant variation was observed from the start until 4 months of storage (Table 2). This result implies that regardless of variety (AES- 1 or AES-2) and sulfite level $(0.1 \%$ or $0.2 \% \mathrm{w} / \mathrm{w})$ the texture did not change much as perceived by the panel. This could be attributed to the presence of sulfites since sulfiting ruptured and collapsed the cells, resulting in a smaller cell volume, and hardness of the dried samples (Moyls, 1981, and Prestamo and Fuster, 1984 as cited in Rahman and Perera, 2007). In addition, Mcfeeters et al. (2004) reported that sulfite prevents rapid softening reaction in red bell peppers. All of the treatments experienced gradual increase and decrease of the intensity scores during storage which could be due to the minimal absorption of moisture by the sample and the effect of sulfite, thereby resulting to the minimal changes of the texture after 4-month storage.

Table 2. Comparison of the sensory properties of the two sulfite level in each variety using Wilcoxon Signed Ranks Test (2-related samples) during 4-month storage.

\begin{tabular}{|c|c|c|c|c|}
\hline \multirow{2}{*}{ Parameter } & \multicolumn{2}{|r|}{ T1vs T2 } & \multicolumn{2}{|r|}{ T3 Vs T4 } \\
\hline & Z & ASYMP. SIG.(2-TAILED) & $\mathrm{Z}$ & ASYMP. SIG.(2-TAILED) \\
\hline \multicolumn{5}{|c|}{$x^{2}$} \\
\hline $0 \mathrm{~m}$ & -1.635 & $.102^{\mathrm{ns}}$ & -1.129 & $.259^{\mathrm{ns}}$ \\
\hline $1 \mathrm{~m}$ & -2.331 & $.020 *$ & -1.526 & $.127^{\mathrm{ns}}$ \\
\hline $2 \mathrm{~m}$ & -1.730 & $.084^{\mathrm{ns}}$ & -.152 & $.879^{\mathrm{ns}}$ \\
\hline $3 \mathrm{~m}$ & -.096 & $.924^{\mathrm{ns}}$ & -.794 & $.427^{\mathrm{ns}}$ \\
\hline $4 \mathrm{~m}$ & -1.745 & $.081^{\mathrm{ns}}$ & -.778 & $.436^{\mathrm{ns}}$ \\
\hline \multicolumn{5}{|l|}{ Aroma } \\
\hline $0 \mathrm{~m}$ & -.155 & $.877^{\mathrm{ns}}$ & -1.440 & $.150^{\mathrm{ns}}$ \\
\hline $1 \mathrm{~m}$ & -1.916 & $.055^{\mathrm{ns}}$ & -1.935 & $.053^{\mathrm{ns}}$ \\
\hline $2 \mathrm{~m}$ & -1.234 & $.217^{\mathrm{ns}}$ & -1.305 & $.192^{\mathrm{ns}}$ \\
\hline $3 \mathrm{~m}$ & -2.125 & $.034 *$ & -1.808 & $.071^{\mathrm{ns}}$ \\
\hline $4 \mathrm{~m}$ & -2.332 & $.020 *$ & -.787 & $.431^{\mathrm{ns}}$ \\
\hline \multicolumn{5}{|l|}{ Flavor } \\
\hline $0 \mathrm{~m}$ & -.300 & $.764^{\mathrm{ns}}$ & -2.572 & $.010 * *$ \\
\hline $1 \mathrm{~m}$ & -.808 & $.419^{\mathrm{ns}}$ & -1.027 & $.304^{\mathrm{ns}}$ \\
\hline $2 \mathrm{~m}$ & -.792 & $.428^{\mathrm{ns}}$ & -.205 & $.838^{\mathrm{ns}}$ \\
\hline $3 \mathrm{~m}$ & -2.556 & $.011 *$ & -.716 & $.474^{\mathrm{ns}}$ \\
\hline $4 \mathrm{~m}$ & -2.161 & $.031 *$ & -1.693 & $.090^{\mathrm{ns}}$ \\
\hline \multicolumn{5}{|l|}{ Aftertaste } \\
\hline $0 \mathrm{~m}$ & -.404 & $.686^{\mathrm{ns}}$ & -1.109 & $.267^{\mathrm{ns}}$ \\
\hline $1 \mathrm{~m}$ & -.215 & $.830^{\mathrm{ns}}$ & -.331 & $.741^{\mathrm{ns}}$ \\
\hline $2 \mathrm{~m}$ & -.290 & $.772^{\mathrm{ns}}$ & -.408 & $.683^{\mathrm{ns}}$ \\
\hline $3 \mathrm{~m}$ & -2.274 & $.023 *$ & -.973 & $.331^{\mathrm{ns}}$ \\
\hline $4 \mathrm{~m}$ & -.319 & $.749^{\mathrm{ns}}$ & -.321 & $.748^{\mathrm{ns}}$ \\
\hline \multicolumn{5}{|l|}{ Texture } \\
\hline $0 \mathrm{~m}$ & -.082 & $.935^{\mathrm{ns}}$ & -.090 & $.928^{\mathrm{ns}}$ \\
\hline $1 \mathrm{~m}$ & -1.519 & $.129^{\mathrm{ns}}$ & -1.133 & $.257^{\mathrm{ns}}$ \\
\hline $2 \mathrm{~m}$ & -1.288 & $.198^{\mathrm{ns}}$ & -.323 & $.746^{\mathrm{ns}}$ \\
\hline $3 \mathrm{~m}$ & -.747 & $.455^{\mathrm{ns}}$ & -1.026 & $.305^{\text {ns }}$ \\
\hline $4 \mathrm{~m}$ & -.176 & $.861^{\mathrm{ns}}$ & -.865 & $.387^{\mathrm{ns}}$ \\
\hline \multicolumn{5}{|l|}{ General } \\
\hline \multicolumn{5}{|l|}{ Acceptability } \\
\hline $0 \mathrm{~m}$ & -.941 & $.347^{\mathrm{ns}}$ & -2.005 & $.045 *$ \\
\hline $1 \mathrm{~m}$ & -2.746 & $.006 * *$ & -.301 & $.763^{\mathrm{ns}}$ \\
\hline $2 \mathrm{~m}$ & -.048 & $.962^{\text {ns }}$ & -.528 & $.598^{\mathrm{ns}}$ \\
\hline $3 \mathrm{~m}$ & -1.470 & $.142^{\mathrm{ns}}$ & -1.167 & $.243^{\text {ns }}$ \\
\hline $4 \mathrm{~m}$ & -1.308 & $.191^{\mathrm{ns}}$ & -2.570 & $.010 * *$ \\
\hline
\end{tabular}

Note: $p$-value $>0.05$, ns $; p$-value $\leq 0.05, *$ (significantly different) $: p$-value $\leq 0.01,{ }^{* *}$ ( highly significant),T1 (AES- $1 \& 0.1 \% \mathrm{w} /$ wsulfite), T2 (AES-1 \& $0.2 \% \mathrm{w} / \mathrm{w}$ sulfite),T3 (AES- $2 \& 0.1 \% \mathrm{w} /$ wsulfite) and T4 (AES-2 \& $0.2 \% \mathrm{w} / \mathrm{w}$ sulfite). 
General acceptability. The general acceptability of the dehydrated jackfruit was not affected significantly with storage until four months for all of the treatments (T1, T2, T3 \& T4) as perceived by the panelists (Table 3). However, comparing T1 and T2, with same variety and differ in sulfite level, a significant difference was observed after 1 month of storage (Table2). Between T3 and T4 a significant difference was noted at 0 and 4 months of storage (Table 2$)$.

Table 3. General acceptability of dehydrated jackfruit during 4 months storage at ambient temperature.

\begin{tabular}{cccccc}
\hline TREATMENT & \multicolumn{5}{c}{ STORAGE, MONTH } \\
& 0 & 1 & 2 & 3 & 4 \\
\hline T1 & $5.16 a$ & $5.12 a$ & $5.20 a$ & $5.04 a$ & $4.92 a$ \\
T2 & $4.96 a$ & $5.68 a$ & $5.16 a$ & $5.40 a$ & $5.20 a$ \\
T3 & $4.92 a$ & $4.88 a$ & $4.96 a$ & $4.88 a$ & $5.20 a$ \\
T4 & $4.28 a$ & $4.92 a$ & $5.08 a$ & $5.04 a$ & $4.40 a$
\end{tabular}

${ }^{1} \mathrm{~N}=3$. Means in the same row with same letters are not significantly $(P \leq 0.05)$ different with each other. T1 (AES-1 \&0.1\% w/w/ Sulfite),T2 (AES-1 \& $0.2 \% \mathrm{w} / \mathrm{w} /$ Sulfite),T3 (AES- $2 \& 0.1 \% \mathrm{w} / \mathrm{w} /$ Sulfite) and T4 (AES-2 \& $0.2 \% \mathrm{w} / \mathrm{w} /$ Sulfite); general acceptability (1-dislike very much to 7 -like very much)

The higher acceptability of T2 than T1 was due to its brighter color (yellow), more aromatic flavor (jackfruitty), and good texture. On the other hand, between T3 and T4, T3 was more acceptable than T4 at the start and at the end of storage period only (Table 3). Maybe this could be attributed to the negative effect of more sulfite on the flavor or taste and color which eventually affected the general acceptability of the product with this variety (AES-2). According to Santos and Pablo (n.d.) as cited in Golosino (2004), the concentration of sodium metabisulfite that gave the best product was $0.05 \%$ and $0.1 \%$.

Microbiological Analysis

Mold count (MC). The MC values of T1 (AES-1 \& $0.1 \% \mathrm{w} / \mathrm{w}$ sulfite) and T2 (AES$1 \& 0.2 \% \mathrm{w} / \mathrm{w}$ sulfite) ranged from 1.00 to $2.16 \mathrm{log} \mathrm{cfu} / \mathrm{g}$ and from 1.00 to $2.02 \mathrm{log} \mathrm{cfu} / \mathrm{g}$, respectively from 0 to 4 months of storage (Table 4). On the other hand, for T3 (AES-2 \& $0.1 \% \mathrm{w} / \mathrm{w}$ ) and T4 (AES-2 \& $0.2 \% \mathrm{w} / \mathrm{w}$ ) the MC ranged from $1.00-1.70 \log \mathrm{cfu} / \mathrm{g}$ and 1.00 $-2.73 \log \mathrm{cfu} / \mathrm{g}$, respectively. T1 showed a decreasing trend from the start until two months and increased after four months. T2, on the other hand, showed a stable MC value from the start until two months; four months after, an increase was observed. Comparing T1 and T2, no difference was observed from the start until 2 months of storage (Table 4).

The result showed that sulfite level did not affect the MC values (Table 4). However, at the end of four months, T1 and T2 were different, where T1 had higher MC value than T2. This result implies the effectiveness of sulfite as antimold. But worth mentioning was the stability of the MC value which was also an effect of sulfite addition which eventually lengthened the shelf life of the product. This observation was in accord with Cerrutti et al. (1998) as cited in Saxena et al. (2009) that the sulphitation had been shown to cause microbial stability in addition to retention of the color attributes.

The MC values of T3 (AES-2 \& $0.1 \% \mathrm{w} / \mathrm{w}$ sulfite) and T4 (AES-2 \& $0.2 \% \mathrm{w} / \mathrm{w}$ sulfite) were not different at 0 and 2 months but as the time progressed, an increase in $\mathrm{MC}$ was observed for both treatments (Table 4). Probably after four months, the sulfite had been depleted already that the concentration left was no longer enough to control the mold 
growth; thus, proliferation of molds was observed.

Comparing T3 and T4, there was no difference observed at the start until two months of storage (Table 4). However, a significant variation was observed after four months where T4 had significantly higher MC than T3. This result implies that the additional $0.1 \%$ (w/w) sulfite of T4 was not effective in controlling the growth of molds for this variety (AES-2). Probably at this time some of the sulfite were still bound that even if T4 had higher sulfite concentration than T3, still no significant reduction occurred.

The effect of variety on the MC values revealed that variety did not affect the MC for the entire duration of storage as shown in Table 4. Moreover, the results showed that both varieties were more stable with respect to MC values than TPC values. Probably this could be due to the higher effectiveness of sulfite against mold than other aerobic microorganisms present in the product. Rahman and Perera (2007) reported that sulfite shows fungicidal and insecticidal properties.

Total plate count (TPC). The TPC values of T1 (AES-1 \& $0.1 \% \mathrm{w} / \mathrm{w}$ sulfite) and T2 (AES-1 \& 0.2\%w/w sulfite) ranged from 2.20-2.84 log cfu/g while for T3 (AES-2 \& $0.1 \%$ $\mathrm{w} / \mathrm{w}$ sulfite) and T4 (AE-2 \& $0.2 \% \mathrm{w} / \mathrm{w}$ sulfite), ranged from 1.00 to $2.84 \mathrm{log} \mathrm{cfu} / \mathrm{g}$. The treatments using AES-1 (T1 and T2) had higher TPC values than AES-2 treatments (T3 and T4) (Table 5). This could be attributed to the higher initial microbial load at the start of storage which was caused by the shorter heat exposure of AES-1 treatments. The TPC values of $\mathrm{T} 1$ increased from 0 to 4 months while $\mathrm{T} 2$ showed a reduction from the start until the second month and maintained until the fourth month. However, there was no difference between T1 and T2 after 2 months (Table 5).

Table 4. Mean ${ }^{1}$ values for MC (log cfu/g) of dehydrated jackfruit during 4 months storage at room temperature.

\begin{tabular}{lccccc}
\hline PARAMETER & VARIETY & TREATMENT & \multicolumn{3}{c}{ STORAGE, MONTH } \\
& & & 0 & 2 & 4 \\
\hline $\begin{array}{l}\text { Mold Count } \\
\text { (MC, } \log \\
\text { cfu/g) }\end{array}$ & AES-1 & T1 & A1.48bA & A1.30cA & A2.16aA \\
& & T2 & A1.00bA & A1.00bA & A2.02 $a \mathrm{~B}$ \\
& AES- 2 & T3 & A1.15bA & A1.00bA & $\mathrm{A} 1.70 a \mathrm{~B}$ \\
& & T4 & A1.15bA & A1.00bA & A2.73aA \\
& & & & & \\
& & &
\end{tabular}

${ }^{1} \mathrm{~N}=3$. Means in the same column with same capital letters before the values are not significantly $(P \leq$ 0.05 ) different with each other (Comparing the variety). Means in the same row with same small letters after the values are not significantly $(P \leq 0.05)$ different with each other. (Comparing counts across storage time). Means in the same column within variety with same capital letters after the values are not significantly $(P \leq 0.05)$ different with each other (Comparing sulfite level in each variety). T1 (AES- $1 \& 0.1 \%$ sulfite), T2 (AES- $1 \& 0.2 \%$ sulfite), T3 (AES- $2 \& 0.1 \%$ sulfite) and T4 (AES- $2 \& 0.2 \%$ sulfite).

At the start of the storage, T1 had a lower value than T2 but after 4 months, T1 had a greater value than T2. Probably at the start of storage some of the sulfite was still bound which had no retarding effect on product deterioration (Rahman and Perera, 2007). However for T2 higher sulfite was effective in controlling aerobic microorganisms, thus a significant reduction of TPC was observed. According to Jay (2000) the antimicrobial action of sulfite was due to the strong reducing power that allowed this compound to reduce $\mathrm{O}_{2}$ tension to a point below by which aerobic organisms can grow or by direct action on some enzyme system.

For AES-2 treatments, T3 (AES-2 and $0.1 \% \mathrm{w} / \mathrm{w}$ sulfite) and T4 (AES-2 and $0.2 \%$ $\mathrm{w} / \mathrm{w}$ sulfite) increased significantly in their TPC from the start to the fourth months of 
storage (Table 5). Moreover, T3 had higher TPC than T4 since T3 had lower sulfite level than T4, considering that sulfite is a good antimicrobial agent (Jay, 2000). Generally, based on the values, microbial proliferation increased with time. However, there was a slow rate because of the incorporation of sulfite in the product. Variety affected the TPC at the start of the storage until two months but after four months it did not cause variation of the TPC values (Table 5). This implies that in the final month of storage, AES-2 and AES-1 had no significant effect on the TPC. The microbial deactivation kinetics depends on several factors like variety, water content, $A_{w}$, temperature, composition of the medium (acidity, types of solids, $\mathrm{pH}$ ), and heating method (Rahman and Perera, 2007).

Comparing TPC values to the microbiological limits for the safety of the products which was set at $<10^{5}$ or $\log \mathrm{cfu} / \mathrm{g} 5.0$ (Gilbert et al., 2000) for dried fruits and vegetables which fell in the third category, the results showed that the product treatments (T1, T2, T3 \& T4) were still acceptable for class A satisfactory after the fourth month. In addition, the 4 treatments were found negative for the presence of E.coli and Salmonella spp. which could prove that these treatments were still safe for human consumption after four months.

Table 5. Mean ${ }^{1}$ values for TPC (log cfu/g) of dehydrated jackfruit during 4 months storage at room temperature.

\begin{tabular}{lccccc}
\hline PARAMETER & VARIETY & TREATMENT & \multicolumn{3}{c}{ STORAGE, MONTH } \\
& & & 0 & 2 & 4 \\
\hline $\begin{array}{l}\text { Total Plate } \\
\text { Count (TPC, }\end{array}$ & AES-1 & T1 & $\mathrm{A} 2.20 c \mathrm{~B}$ & $\mathrm{~A} 2.62 b \mathrm{~A}$ & $\mathrm{~A} 2.84 a \mathrm{~A}$ \\
$\log \mathrm{cfu} / \mathrm{g})$ & & $\mathrm{T} 2$ & $\mathrm{~A} 2.76 a \mathrm{~A}$ & $\mathrm{~A} 2.58 b \mathrm{~A}$ & $\mathrm{~A} 2.56 b \mathrm{~B}$ \\
& $\mathrm{AES}-2$ & $\mathrm{~T} 3$ & $\mathrm{~B} 1.00 c \mathrm{~A}$ & $\mathrm{~B} 2.23 b \mathrm{~A}$ & $\mathrm{~A} 2.84 a \mathrm{~A}$ \\
& & $\mathrm{~T} 4$ & $\mathrm{~B} 1.00 c \mathrm{~A}$ & $\mathrm{~B} 1.69 b \mathrm{~B}$ & $\mathrm{~A} 2.27 a \mathrm{~B}$ \\
& & & & \\
\hline
\end{tabular}

${ }^{1} \mathrm{~N}=3$. Means in the same column with same capital letters before the values are not significantly $(P \leq$ $0.05)$ different with each other (Comparing the variety). Means in the same row with same small letters after the values are not significantly $(P \leq 0.05)$ different with each other. (Comparing counts across storage time). Means in the same column within variety with same capital letters after the values are not significantly $(P \leq 0.05)$ different with each other (Comparing sulfite level in each variety). T1 (AES- $1 \& 0.1 \%$ sulfite), T2 (AES- $1 \& 0.2 \%$ sulfite), T3 (AES- $2 \& 0.1 \%$ sulfite) and T4 (AES- $2 \& 0.2 \%$ sulfite).

\section{CONCLUSION}

It can be concluded therefore, that as the storage time was increased, the color deteriorated due to browning reaction. However, there was a slow recurrence of the changes of the sensory qualities which can be attributed by the variety and sulfite levels. This contributed to the increase of the shelf life of dehydrated jackfruit which resulted to the quality and safety of the product.

\section{ACKNOWLEDGMENT}

Special thanks is extended to the graduate advisory committee, VSU, DOST, PCAARRD, CHED, DA-BAR, and NRCP for the financial support provided to the author. 


\section{REFERENCES}

ABRAHAM,D. G. RODIMEIRE, M. RODRIGUES, S. S. CARLA, and C.F. AMANDA. 2004. The air drying behavior of osmotically dehydrated for jackfruit (Artocarpus heterophyllus L.) slices. Proc. Of the $14^{\text {th }}$ International Drying Symposium, Brazil. Vol. C, PP:2120-2126.

ASHIE, I.N.A. and B.K. SIMPSON. 1996. Application of high hydrostatic pressure to control enzyme related fresh seafood texture deterioration. Food Res. Inter., 29:569-575.

CORONEL, R.E. 1983. Promising Fruits of the Philippines. Published by the College of Agriculture, U.P. Los Baños, Laguna Philippines. pp 251

CRUZ , R.T. DELA. 2002. A Second Look at Jackfruit. BAR Chronicle, a monthly publication. Vol 3 No. 6 dated March 16-31, 2002. http://www.bar.gov.ph/barchronicle/2002/mar02_16-31_a second.asp (retrieved 11-20-09).

DIAMANTE,L.M. 2005. Development of Food Products from Jackfruit.Unpublished Research Proposal. OVPRE. Visayas State University,Visca, Baybay City, Leyte.

EL-AOUAR, A.A., P.M. AZOUBEL, and F.E.X. MURR. 2003. Drying kinetics of fresh and osmotically pre-treated papaya (Carica papaya L.). Journal of Food Engineering 59:8591.

ESKIN, N.A.M. 1990. Biochemistry of Foods. Second edition. Academic Press, Inc. New York. 557 pp.

GILBERT, R.J., J. DE LOUVOIS, T. DONOVAN, C. LITTLE, K. NYE, C.D. RIBEIRO, J. RICHARDS, D. ROBERTS, and F.J. BOLTON. 2000. (A working group of the PHLS advisory committee for Food and Dairy Products). 2000. Guidelines for the microbiological quality of some ready-to-eat foods sampled at the point of sale. Commun Dis Public Health 3:163-167.

GOLOSINO, G.M. 2004. Effect of level of citric acid on the drying characteristics and sensory qualities of dehydrated sweetened jackfruit (Artocarpus heterophyllus Lam.) with added ascorbic acid. BSFT Thesis. LSU,Visca, Baybay,Leyte. 55p.(Available at the University Library).

JAY, J. M. 2000. Modern Food Microbiology. $6^{\text {th }}$ ed. Aspen Publishing, Inc. Maryland, USA $625 \mathrm{pp}$.

KONOPACKA, D., K. JESIONKOWSKA, R. KLEWICKI, and C. BONAZZI. 2009. The effect of different osmotic agents on the sensory perception of osmo-treated dried fruit. Journal of Horticultural Science and Biotechnology. ISAFRUIT Special Issue pp.80-84.

LAMBRECHT, H.S. 1995. Sulfite substitutes for the prevention of enzymatic browning in foods.In: Lee C.Y and Whitaker, J.R. (Eds.) Enzymatic browning and its prevention. American Chemical Society, Washington D.C. pp 313-323.

MABESA, L.B. 1986. Sensory evaluation of foods: Principles and Methods. Published by: College of Agriculture, University of the Philippines, Los Baños, College, Laguna.119 pp.

MARSHALL, M.R., J. KIM, and C.I. WEI. 2000. Enzymatic browning in fruits, vegetables and Seafoods. In FAO. http://www.fao.org/ag/Ags/agsi/ENZYMEFINAL/ enzymatic browning.html. retrieved: Nov. 26,2009.

MCFEETERS, R.F., L.M. BARRAANGOU, A.O. BARISH, and S.S. MORRISON. 2004. Rapid Softening of Acidified Peppers: Effect of Oxygen and Sulfite. J. Agric. Food Chem. 52:4554-4557.

RAHMAN, M.S. and C.O. Perera. 2007. Drying and Food Preservation. In RAHMAN, M.S, (Ed). Handbook of food preservation. Second edition. CRC Press, Taylor and Francis Group, New York. Pp. 403-432. 
SAXENA, A., A.S. BAWA, and P.S. RAJU. 2008. Use of modified atmosphere packaging to extend shelf-life of minimally processed jackfruit (Artocarpus heterophyllus L.) bulbs. Journal of Food Engineering 87 (4):455-466.

SAXENA, A., A.S. BAWA, and P.S. RAJU. 2009. Optimization of a multitarget preservation technique for jackfruit (Artocarpus heterophyllus L.). Journal of Food Engineering 91(1):18-28. 